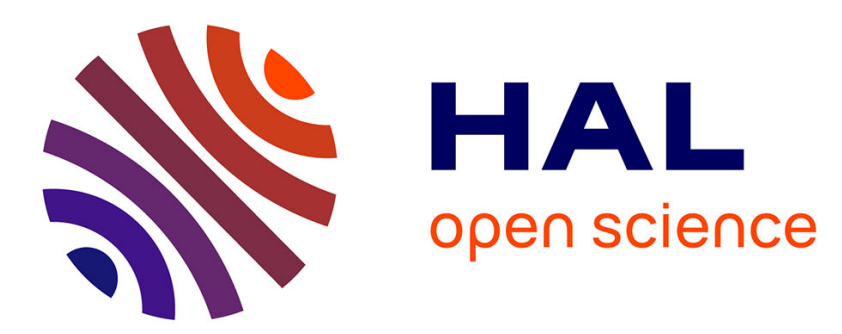

\title{
A microdrop generator for the calibration of a water vapor isotope ratio spectrometer
}

Rosario Iannone, D. Romanini, Samir Kassi, Harro A.J. Meijer, E. R. T.

Kerstel

\section{- To cite this version:}

Rosario Iannone, D. Romanini, Samir Kassi, Harro A.J. Meijer, E. R. T. Kerstel. A microdrop generator for the calibration of a water vapor isotope ratio spectrometer. Journal of Atmospheric and Oceanic Technology, 2009, 26, pp.1275. 10.1175/2008JTECHA1218.1 . hal-00563787

\section{HAL Id: hal-00563787 \\ https://hal.science/hal-00563787}

Submitted on 7 Feb 2011

HAL is a multi-disciplinary open access archive for the deposit and dissemination of scientific research documents, whether they are published or not. The documents may come from teaching and research institutions in France or abroad, or from public or private research centers.
L'archive ouverte pluridisciplinaire HAL, est destinée au dépôt et à la diffusion de documents scientifiques de niveau recherche, publiés ou non, émanant des établissements d'enseignement et de recherche français ou étrangers, des laboratoires publics ou privés. 


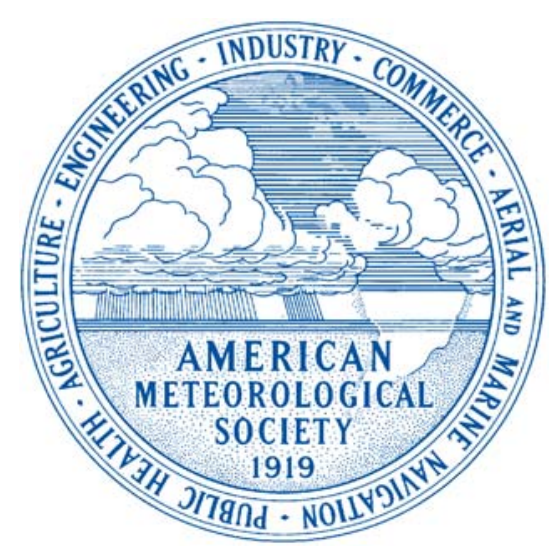

\section{AMERICAN \\ METEOROLOGICAL SOCIETY}

Journal of Atmospheric and O ceanic Technology

\section{EARLY ONLINE RELEASE}

This is a preliminary PDF of the author-produced manuscript that has been peer-reviewed and accepted for publication. Since it is being posted so soon after acceptance, it has not yet been copyedited, formatted, or processed by AMS Publications. This preliminary version of the manuscript may be downloaded, distributed, and cited, but please be aware that there will be visual differences and possibly some content differences between this version and the final published version.

The DOI for this manuscript is doi: $10.1175 / 2008 J T E C H A 1218.1$

The final published version of this manuscript will replace the preliminary version at the above DOI once it is available. 
2

A microdrop generator for the calibration of a water vapor isotope ratio spectrometer

4

5 Rosario Q. Iannone ${ }^{1}$, Daniele Romanini ${ }^{2}$, Samir Kassi ${ }^{2}$, Harro A. J. Meijer ${ }^{1}$ and Erik

6

R. Th. Kerstel ${ }^{1}$

7

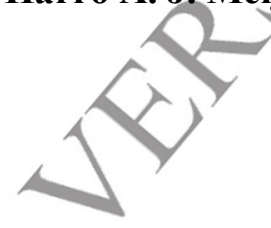

$8{ }^{1}$ Centrum voor IsotopenOnderzoek (CIO), University of Groningen, 9747 AG Groningen, The Netherlands

${ }^{2}$ Laboratoire de Spectrométrie Physique CNRS UMR5588, J. Fourier University of Grenoble, 


\section{Abstract}

2 A microdrop generator is described to produce water vapor with a known isotopic

3 composition and volume mixing ratio for the calibration of a near-infrared diode laser water

4 isotope ratio spectrometer. The spectrometer is designed to measure in-situ the water vapor

5 deuterium and oxygen $\left({ }^{17} \mathrm{O}\right.$ and $\left.{ }^{18} \mathrm{O}\right)$ isotope ratios from the low troposphere up to the lower

6 stratosphere with a high temporal resolution, and is based on ultra-sensitive optical-feedback

7 cavity enhanced absorption spectroscopy.

8 To calibrate the spectrometer, a commercial microdrop generator (Microdrop $\mathrm{GmbH}$ ) is used

9 to inject water droplets of known size at a preset repetition frequency into a stream of dry

10 nitrogen or synthetic air. Complete evaporation of the small droplets assures that there is no

11 isotopic fractionation between the liquid phase and the generated moist "air". The water

12 mixing ratio of the synthetic air is controlled by the repetition rate and gas flow.

13 The current system spans a water mixing ratio range from about 10 to 5,000 ppmv, 14 representing the range of conditions expected in the low to upper troposphere. Both lower and

15 higher mixing ratios can be produced after small modifications to the injector operating 16 conditions or the system design. 


\section{1. Introduction}

2

3 Water vapor is a key element in the global climate, as it is the most active greenhouse gas. In

4 the troposphere, water is responsible for the global movement of latent heat and it affects

5 cloud cover, which controls radiation and cooling rates. In the stratosphere, water vapor

6 affects ozone levels through its involvement in the production of odd-hydrogen and the

7 formation of stratospheric clouds (Kirk-Davidoff et al., 1999; Forster and Shine, 2002). In-

8 situ measurements of isotope ratios in atmospheric moisture are believed to be vital to the

9 study of these phenomena. (Moyer et al., 1996; Keith, 2000; Schmidt et al., 2005; Toon et al., 10 2003).

11 Lower in the troposphere the study of the hydrological cycle provides important contributions

12 to our understanding of the global carbon budget, as the hydrological and carbon cycles are

13 linked through the exchange of oxygen atoms in the ecosystem (Yakir and da S.L. Sternberg, 14 2000; Wang and Yakir, 2000). Isotope measurements directly on the vapor compartment of the hydrological cycle represent also the missing link in the validation of global circulation modeling efforts. Currently such models are not able to correctly describe the isotopic composition of precipitation in polar regions, and in fact do not agree with each other (Hoffmann et al., 2000; Werner and Heimann, 2002; Helsen et al., 2004). Still, such models are supposed to put the use of ice-core isotope data as a temperature proxy on a firm physical basis.

The usefulness of water isotopologues stems from the fact that the isotopologues of a molecule such as $\mathrm{H}_{2} \mathrm{O}$ exhibit small differences in their physical and chemical behavior, resulting in isotope fractionation during physical, chemical and biological processes. Thus, abundance ratios of the stable water isotopologues provide an additional mass-balance 
1 equation and give information on the history of an air parcel, which may, for example, be

2 used to help understand the transport of water from the troposphere to the stratosphere. In

3 ecological studies, the strong feedback of vegetation to the atmosphere results in considerable

4 differences in isotopic composition between the highly depleted soil and enriched leaf water.

5 These large differences are the basis for separating the two ecosystem water flux components

6 of transpiration and evaporation (Yepez et al., 2003; Williams et al., 2004).

7

8 The isotopic composition is reported in the " $\delta$ " notation, giving the enrichment (most 9 commonly expressed in per mil, denoted by \%o) relative to a reference material:

$$
\delta=\left(R_{\text {sample }} / R_{\text {reference }}-1\right)
$$

Here, $R$ represents the ratio of the rare to the abundant isotope in the sample or the reference material. The international standard reference material used for the measurements of ${ }^{2} \mathrm{H}$ and ${ }^{18} \mathrm{O}$ in water is VSMOW (Vienna Standard Mean Ocean Water), which therefore by definition has $\delta^{2} \mathrm{H}, \delta^{17} \mathrm{O}$, and $\delta^{18} \mathrm{O}$ values equal to zero. If $\delta$ is positive the sample is "enriched", whereas if $\delta$ is negative the sample is said to be "depleted" relative to the standard.

Unfortunately, atmospheric water vapor and its isotopic composition are extremely difficult to measure for a variety of reasons, including:

i. Water vapor in the atmosphere is characterized by the fact that its concentration spans a range of over four orders of magnitude. Water vapor levels decrease from around 20,000 ppm at ground level to about $5 \mathrm{ppm}$ at high altitudes (in the lower stratosphere). 
1 ii. The high affinity of water for instrument surfaces: water vapor adsorbs on nearly all surfaces with an associated isotopic fractionation. This serious problem can potentially cause significant systematic errors in the determination of the water vapor isotope ratios, as well as concentration, especially at very low concentration.

iii. The high variability on short spatial and temporal scales. The temporal and spatial distribution of water vapor is complex and local because its spatial distribution is often strongly related to temperature (Pielke, 2001).

iv. In addition, carrying out measurements in the higher troposphere and lower stratosphere means working in a harsh environment where temperature and pressure are low with obvious consequences for the thermal design of the instrument (with the balloon or aircraft platform presenting its own specific difficulties).

Isotope measurements are usually carried out by Isotope Ratio Mass Spectrometry (IRMS). The IRMS technology has achieved high levels of precision. The main drawback, however, is that IRMS is incompatible with condensable gases, and in particular with a sticky molecule like water. Sample preparation in this case is complicated, requiring that the isotope ratios of interest be transferred to another molecule, for example, by reduction of water to $\mathrm{H}_{2}$ for the determination of $\delta^{2} \mathrm{H}$ and equilibration of water and carbon dioxide for the determination of $\delta^{18} \mathrm{O}$ (Kerstel, 2004; Kerstel and Meijer, 2005). But in this case, a direct measurement of the $\delta^{17} \mathrm{O}$ isotope ratio is difficult due to mass overlap with ${ }^{13} \mathrm{CO}_{2}$. An alternative mass spectrometric technique, in which water is reacted with cobalt fluoride to produce molecular oxygen gas, was described by Baker et al. (2002).

Moreover, IRMS instruments are voluminous and heavy, and for this reason alone not suitable for in-situ measurements. A possible solution would be the use of a cryogenic sampling device to collect samples, in combination with a laboratory based isotope analysis 
1 by IRMS (or a laser-based technique). For tropospheric and ecological measurements such an

2 approach has been used by Helliker et al. (2002) and West et al. (2006), respectively.

3 Franz and Röckmann (2004) have shown that this approach can be successful, if executed

4 with extreme care, even for studies at very low water mixing ratio, such as encountered high

5 in the troposphere and in the lower stratosphere. They modified a continuous flow IRMS

6 system to be able to analyze liquid water samples as small as $120 \mathrm{~nL}$. The precision reported

7 is $7 \%$, $0.7 \%$, and $1.3 \%$ for $\delta^{2} \mathrm{H}, \delta^{17} \mathrm{O}$, and $\delta^{18} \mathrm{O}$, respectively. This system was subsequently

8 used to analyze lower stratospheric air samples collected in small $(\sim 150 \mathrm{~mL})$ cryogenic traps

9 for $\delta^{17} \mathrm{O}$ and $\delta^{18} \mathrm{O}$ (Franz and Röckmann, 2005). Although the precision on the oxygen

10 measurements is $3-4 \%$, the errors of the individual samples are correlated, resulting in

11 measurement errors as low as $0.3 \%$ for the $\Delta^{17} \mathrm{O}$-anomaly $\left(\approx \delta^{18} \mathrm{O}-0.528 \cdot \delta^{17} \mathrm{O}\right)$. Still, such an

12 approach is complex and carries a high risk of failure, and, more principally, offers a poor

13 temporal and spatial resolution.

15 Recent advantages in the laser field have improved in-situ measurements of atmospheric trace 16 gases, as alternative to more conventional methods. Semiconductor lasers enable the 17 development of compact, stable and reliable spectrometers. Diode-laser spectrometry offers 18 several advantages over mass spectroscopy for precise in-situ measurements at low 19 concentrations. The measurements are simple, direct, and do not require appropriate sample 20 preparations, although calibration with standard gases remains necessary.

In 2003, we developed a compact diode-laser spectrometer, named Groningen-Grenoble

23 Water Isotope Spectrometer (G2WIS), for in-situ measurement of stratospheric water isotope 24 ratios. The technique used is Optical Feedback Cavity Enhanced Absorption Spectroscopy 25 (OF-CEAS) (Morville et al., 2004, 2005; Kerstel et al., 2006), which is in essence a variation 
1 on the technique of Cavity Ring Down Spectroscopy (CRDS) (for a review see: Berden et al.,

22000 or Mazurenka et al., 2005), enabling the realization of very long effective absorption

3 path lengths $(\sim 6 \mathrm{~km})$ with a very compact optical arrangement.

4

5 In May 2004, this device participated in an engineering test flight on board of the NASA DC-

68 research aircraft, in Dryden, California. Data was collected at altitudes from $300 \mathrm{~m}$ above

7 ground up to $12.5 \mathrm{~km}$. The device performed well during these flights, showing precision

8 levels of $9 \%$, $3 \%$, and $1 \%$, for $\delta^{2} \mathrm{H}, \delta^{17} \mathrm{O}$, and $\delta^{18} \mathrm{O}$, respectively, for 10 -sec averaged data

9 obtained during level flight, where the measured water mixing ratio was of the order of 1000

10 ppmv.

11 A new version of the spectrometer was built for integration on the M55 Geophysica 12 stratospheric airplane. The device is compact and power efficient $(50 \mathrm{~kg}$ and $150 \mathrm{~W}$, 13 respectively, including pump and all electronics). This version of the spectrometer was named 14 IRIS (water Isotope Ratio Infrared Spectrometer), and participated in the European AMMA 15 (African Monsoon Multidisciplinary Analysis) campaign out of Ouagadougou, Burkina Faso, 16 in the summer of 2006 (Iannone et al., 2009).

18 The great interest in the application of the water vapor stable isotopes ${ }^{2} \mathrm{H}$ and ${ }^{18} \mathrm{O}$ has also led 19 to the development of laser-based isotope ratio spectrometers by a number of other academic 20 groups, as well as commercial developments by different companies.

22 Recently, in-situ measurements of the isotopic content of water vapor in the upper 23 troposphere and lower stratosphere onboard the NASA WB-57 aircraft platform were 24 performed by Hanisco and colleagues (2007). Their mid-IR spectrometer is based on the 25 technique of Off-Axis Cavity Enhanced Absorption Spectroscopy (OA-CEAS), better known 
1 as Off-Axis Integrated Cavity Output Spectroscopy (OA-ICOS), and uses a cryogenically

2 cooled mid-infrared quantum cascade laser (QCL). The size and volume alone would make

3 this spectrometer not suitable for more wide-spread application to tropospheric measurements.

5 Lee et al. (2005) carried out ground-based continuous measurements of $\delta^{18} \mathrm{O}$ in atmospheric 6 water vapor, in New Haven, Connecticut (USA), using a commercial tunable diode laser gas 7 analyzer (Campbell Scientific) based on direct absorption spectroscopy with a cryogenically 8 cooled lead-salt diode laser.

9 Two other companies developed water vapor isotope analyzers, both using a high-finesse optical cavity to increase the sensitivity, while using a near-infrared laser source that operates

11 in the spectral region near $1.39 \mu \mathrm{m}$, as used in our instrument (Picarro 2008; Los Gatos 2008).

13 All water vapor isotope ratio analyzers mentioned here above require an accurately performed 14 calibration, irrespective of the exact methodology used. Gas analyzers need, in fact, to be 15 periodically calibrated to ensure system integrity and sensor accuracy. In case of concentration only measurements, span calibration can be performed, which involves the measurement of a gas mixture at a number of known concentration levels (Werle et al., 2005), whereas for isotope ratio determination, it is necessary to use a series of samples with 19 different, but well-known, isotopic composition (Kerstel, 2004; Kerstel and Gianfrani, 2008, 20 and references therein). It may be necessary to repeat this procedure at different water mixing 21 ratios, if the spectrometer is to be used over an extended range of mixing ratios, as it can in general not be taken for granted that the spectrometer calibration is independent of the water

23 concentration. This is, for example, demonstrated in the work on liquid water samples by 24 Kerstel et al. (1999) and Lis et al., (2008). In both cases, this behavior is principally due to 25 unequal sample mass, and thus unequal total pressure, in the gas cell(s) during the sample and 
1 the reference measurement, in combination with a data analysis procedure that fails (in fact,

2 was not designed) to retrieve the true area of the spectral absorption profile, and therewith the

3 isotopologue number density. Kerstel et al. (1999) showed that the differential pressure

4 induced apparent isotope shift could be adequately modeled by taking the details of their data

5 analysis procedure into account. However, the measurements on atmospheric moisture by Lee

6 et al. (2005) were carried out at constant pressure, but still show a dependence of the isotope

7 determination on the water mixing ratio. In this case, the most likely explanation is a non-

8 linear response of the detector, an improper accounting for the detector dark-current, or

9 systematic errors made in the determination of the spectral background. The problem was

10 addressed by dynamically adjusting the volume mixing ratio of the reference vapor stream to

11 bring the absorption signals on the reference measurement at the same level as those of the

12 sample (i.e., outside atmospheric air) measurement (Lee et al., 2005).

14 Up to now, the standard method to calibrate a water vapor isotope or concentration analyzer 15 relied on the production, by means of a dew point generator, of a moist air stream whose vapor content is determined by thermodynamic equilibrium conditions, and for which the

17 isotope ratios are assumed to follow the Rayleigh distillation model.

18 This method is described by Franz and Röckmann (2005) and by Lee et al. (2005), who both 19 used a (commercial) dew point generator as a Rayleigh distillation device. The dew point 20 generator is able to produce a stable water vapor mixing ratio by saturating dry nitrogen or air 21 at a well-known and stable temperature and pressure. The dew point generator reservoir is 22 first flushed several times, and then filled with water of known isotopic composition. Dry air 23 is bubbled through the temperature stabilized reservoir of the dew point generator, and the 24 moist stream coming out of the device is sent to the spectrometer. The isotopic composition of 25 the vapor is related to that of the liquid in the reservoir through generally well-known, but 
1 temperature dependent, isotope fractionation factors. Since the liquid water in the reservoir of

2 the dew point generator becomes progressively enriched in the heavier isotopes, the vapor

3 will not show a constant isotopic composition over time, but will also become increasingly

4 heavier. This approach, therefore, requires knowledge of the thermodynamic equilibrium and

5 known isotope fractionation factors, as well as a determination of the (change in) isotopic

6 composition of the water in the reservoir. Using a dew point generator, it is not practically

7 feasible to rapidly change between standard waters of different isotopic compositions, and, in

8 view of the relatively large quantities of water involved, using water samples with different

9 isotopic compositions can become expensive, and is in any case not practical for field

10 applications.

11 Therefore, Lee et al. (2005) also used a dripper device, in order to generate a reference stream

12 with known isotopic composition. In this case the vapor was generated using a syringe pump,

13 which was programmed to dispense the liquid at a precise rate into a flask flushed with dry

14 air. As long as the water released evaporates completely, there will be no isotopic

15 fractionation between the supplied liquid phase and the generated moist stream.

16 Both methods described above, the dew point generator and the dripper device, have in

17 common that they can produce air streams with high water mixing ratios typical of 18 tropospheric conditions, but require mixing of the air stream with a secondary dry air stream

19 to reach the low mixing ratios typical of the upper troposphere and lower stratosphere. The

20 lowest water mixing ratio achieved by Lee et al., using the dew point generator without

21 subsequent mixing with dry air, was $\sim 2,500 \mathrm{ppm}$, whereas the dripper device was able to

22 produce water mixing ratios from $800 \mathrm{ppm}$ up to 30,000 ppm (Lee et al., 2005). 
1 The aim of this paper is to describe a novel approach to produce a moist air stream with a

2 calibrated water mixing ratio and of known isotopic composition that spans practically the

3 entire range encountered in the upper and lower troposphere.

4 A similar approach has been employed by St. Clair (2008) to calibrate the measurements of

$5 \quad \mathrm{H}_{2} \mathrm{O}$ and $\mathrm{HDO}$ in the upper troposphere and lower stratosphere, using Hoxotope, an

6 instrument based on a combination of photolysis and laser induced fluorescence (LIF). Unlike

7 our instrument, Hoxotope has been exposed to a very small span of mixing ratios (200 ppmv).

8

9 To demonstrate the device, we report the results of the laboratory characterization of an OFCEAS spectrometer (G2WIS), developed in our laboratories for the airborne measurement of water vapor isotopes in the lower atmosphere.

\section{Experimental}

Our approach consists of using a commercial, piezoelectric droplet generator, hereafter referred to as microdrop generator or, even shorter, injector, to inject water droplets of predetermined (sub-nanoliter) volume at a preset repetition frequency into a stream of dry nitrogen or dry synthetic air. The injector's micro-dispenser technology is based on the same principle as inkjet printer nozzle technology (de Gans and Schubert, 2003; Meinhart and Zhang, 2000). The ejected fluid volume in these devices depends mainly on the geometrical dimensions of the nozzle and is influenced by liquid properties like surface tension and viscosity, as we will see later. The water volume mixing ratio of the generated moist air stream is most easily controlled by changing the repetition frequency of the injector. The range of mixing ratios that can be reached is further determined by the mass flow rate of the carrier gas. Here we use the injector to produce water mixing ratios over almost three orders of magnitude, from 12 to $7,600 \mathrm{ppm}$. The water isotopic composition of the moist stream is 
1 equal to that of the liquid sample supplied to the injector, since the small size of the droplets

2 assures their complete evaporation. This is a major advantage, especially compared to the case

3 of the dew point generator.

4

\section{$5 \quad 2.1$ The microdrop generator}

6 The injector (Microdrop GmbH, model MD-K-130) consists of a glass capillary, with a $30 \mu \mathrm{m}$

7 diameter nozzle at the end, surrounded by a piezo ceramic tube. A voltage pulse applied to the

8 piezoelectric element produces a shockwave in the fluid contained inside the glass capillary,

9 forcing single droplets to be ejected from the nozzle with a well reproducible volume $(<1 \%$

10 variation under constant operating conditions (Lee 2002)) and with a velocity of

11 approximately $2 \mathrm{~m} / \mathrm{s}$. In order to observe the droplets, an external CCD camera and a light

12 emitting diode (LED) are used. When the stroboscopic light pulses, emitted by the LED, are

13 in resonance with the injector driving frequency, the falling droplet can be "frozen" on the

14 CCD camera screen.

15 Figure 1 shows four sequences in the water droplet formation and ejection from the nozzle. In

16 the first frame, the fluid is propelled towards the orifice. Subsequently, the fluid is pulled-

17 back. Break-up of the fluid column generates a small micro-drop that is ejected from the

18 nozzle. The droplet formation is viewed at different times using a variable delay between the

19 driving pulse and the strobe flash. As the delay is increased, the effect is to produce a slow-

20 motion picture of the formation of the droplet.

22 The injector's glass capillary is connected to the water reservoir through a 23 polytetrafluorethylene (PFTE) tube. The micro dispenser injector is located in a small 24 aluminum housing, $40 \mathrm{~mm}$ wide and $40 \mathrm{~mm}$ height. The droplets can travel up to $5 \mathrm{~mm}$ from 25 the injector nozzle before hitting the bottom of the housing. 
2 In order to generate the droplet, the liquid column inside the glass capillary of the injector

3 must gain sufficient inertia momentum to surmount the effects due to the surface tension and

4 viscous forces. The Reynolds number is the relevant parameter here, giving the ratio of the

5 inertial drag force to the viscous drag force. In our case, with water as the working fluid, and

6 assuming a temperature of $20^{\circ} \mathrm{C}$, a velocity of $2 \mathrm{~m} / \mathrm{s}$, dynamic viscosity $\eta$ of $10^{-3} \mathrm{~kg} \cdot \mathrm{m}^{-1} \cdot \mathrm{s}^{-1}(=$

$7 \quad 1 \mathrm{mPa} \cdot \mathrm{s}$ ), density of $998 \mathrm{~kg} / \mathrm{m}^{3}$, and finally a nozzle diameter of $30 \mu \mathrm{m}$, the Reynolds

8 number is about 60 . This is sufficiently low that the flow inside the injector nozzle is laminar

9 (Squires and Quake, 2005). Under these conditions the droplet size is determined principally

10 by the nozzle size, but may vary with the liquid viscosity, the exact details of the pulse train

11 applied to the piezoelectric actuator, and the pressure differential over the injector capillary

12 and nozzle (E. R. Lee, 2002). For a detailed description of the physics of the microdrop

13 generator we refer to Lee (2002).

14 A droplet mass of $49.6 \pm 0.2 \mathrm{ng}$ (corresponding to a volume of $49.7 \mathrm{pL}$ ) was determined 15 experimentally by collecting the amount of water produced by the injector over a 3-hour

16 period when driven at $400 \mathrm{~Hz}$ in a small flask. The droplet mass is then determined by

17 dividing the difference of final and initial mass of the flask by the product of repetition 18 frequency and measurement time.

19 This result compares well to the $48 \mathrm{pL}$ specified by the manufacturer, based on a measured 20 diameter of $45 \mu \mathrm{m}$ and the assumption of a spherical droplet.

21 A limitation of the injector system, in its present configuration, is that, at a flow rate of 150 $22 \mathrm{~mL} / \mathrm{min}$, the generated water mixing ratio should not exceed $\sim 3,500 \mathrm{ppmv}$ by much. Above 23 this value, the droplets no longer evaporate completely before hitting the bottom of the 24 injector housing. Permanent wetting of the inside of the injection chamber now occurs, which 
1 was verified by observing the bottom of the injection chamber with the CCD camera. This is

2 accompanied by isotope fractionation of the water sample and a slow time-response.

3 Figure 2 represents a diagram of the gas handling system used to perform the measurements

4 of the water vapor isotopes, generated by the injector. A high-pressure tank of dry nitrogen is

5 equipped with a standard pressure regulator, which brings the pressure down to about 3 bars.

6 Although the certified amount of water is $<5 \mathrm{ppm}$, the actual concentration is more likely less

7 than $\sim 1 \mathrm{ppm}$ (see below, paragraph 3.1). Therefore, no effort was made to further dry the

8 nitrogen. For high-precision isotope measurements at the lowest water concentrations, further

9 drying of the nitrogen gas is recommended. Subsequently, a pressure controller (Combo,

10 model PR50A15Z1) regulates the pressure in the gas line to approximately 30 mbar above

11 ambient pressure, in order to avoid water leaking from the injector nozzle. Control of the

12 differential pressure is also important in assuring a constant performance of the injector in

13 terms of droplet size (E.R. Lee, 2002). The dry air stream then enters into and out of the

14 injection chamber through $4.5 \mathrm{~mm}$ inner diameter tubes. The injection chamber itself

15 measures ca. $12 \mathrm{~mm}$ in diameter and $6 \mathrm{~mm}$ in height. With this height the droplets can travel

$16 \sim 5 \mathrm{~mm}$ before hitting the bottom.

17 The CCD camera axis of view is perpendicular to the plane of the drawing. The moist air 18 stream, passing a flow meter, is led to the infrared water isotope spectrometer. The gas lines

19 are made of hydrophobically coated (Restek Corp.) stainless steel tubing.

21 Measurements with the injector were performed on three local water standards, GS-22, GS-48 and GS-50, whose isotopic compositions are very well known through repeated IRMS 23 analyses at our institute. The GS-48 standard has an isotopic composition of $(-43.3 \pm 0.3) \%$ for $24 \delta^{2} \mathrm{H}$ and $(-6.52 \pm 0.03) \%$ for $\delta^{18} \mathrm{O}$, while the GS-50 standard has a value of $(-276.7 \pm 0.3) \%$ and 25 (-35.01 \pm 0.03$) \%$ for $\delta^{2} \mathrm{H}$ and $\delta^{18} \mathrm{O}$, respectively. At $(-113.5 \pm 0.3) \%$ and $(-15.29 \pm 0.03) \%$ for 
$1 \delta^{2} \mathrm{H}$ and $\delta^{18} \mathrm{O}$, respectively, the isotopic composition of GS-22 is between those of GS-48 and

2 GS-50. All values are with respect to the international VSMOW-SLAP scale (Gonfiantini,

3 1984). For all three local water standards, the ${ }^{17} \mathrm{O}$ isotope ratio was independently measured

4 and found to follow mass dependent fractionation within the measurement uncertainty (Meijer

5 and $\mathrm{Li}, 1998)$.

6 Two microdroplet generators were employed, one for GS-48, the other for GS-22 and GS-50,

7 enabling a more rapid switching between the reference materials.

\section{$9 \quad 2.2$ Infrared laser spectrometric water vapor measurements}

10 The moist air streams produced with the microdrop generator were analyzed for their water

11 isotopic composition using the G2WIS infrared laser based spectrometer. The absorption

12 technique exploited here is based on a high-finesse optical cavity in which the light intensity

13 transmitted at the cavity resonances is measured, as a narrowband laser is swept across them.

14 A distinguishing feature of the technique is the use of optical feedback to a semiconductor

15 laser (hence OF-CEAS), in order to significantly improve the intensity and stability of the

16 transmitted light (Morville et al., 2005). From time to time (at least once per spectral scan in

17 an automated procedure) the decay rate of photons inside the cavity is measured in order to

18 normalize the absorption scale (Kerstel et al., 2006). This periodic determination of the cavity

19 ring down time, in combination with an equidistant frequency scale determined by the cavity

20 free spectral range, assures a highly accurate measurement of the absorption coefficients used

21 to evaluate the volume mixing ratio and the isotope ratios.

22 The laser spectrometer scans between selected $\mathrm{H}_{2}{ }^{16} \mathrm{O},{ }^{2} \mathrm{H}^{16} \mathrm{O}{ }^{1} \mathrm{H}, \mathrm{H}_{2}{ }^{17} \mathrm{O}$, and $\mathrm{H}_{2}{ }^{18} \mathrm{O}$ absorption

23 lines to provide nearly simultaneous detection of their absorption coefficients. Data are

24 acquired at a rate of $\sim 10$ spectra per second, but usually averaged over longer periods to

25 improve the signal-to-noise ratio. Dicke-narrowed Voigt line shapes, using the Rautian hard- 
1 collision model (Rautian and Sobel'man, 1967), were fit to all spectral features to retrieve the

2 areas associated with the individual spectral lines, and thus indirectly the isotopologue

3 number densities.

4 The principle of laser spectroscopy depends on the fact that the amount of light absorbed by a 5 sample is related to the concentration of the gas species present in the sample. The Lambert6 Beer law relates the incident light intensity $I_{0}$ to the transmitted light intensity $I$ :

7

8

9 24 into account.

$$
I=I_{0} \mathrm{e}^{-\alpha(\lambda) l}
$$

where $\alpha$ is the absorption coefficient of the sample at the wavelength $\lambda$, and $l$ is absorption path length. The wavelength dependent absorption coefficient $\alpha$ can be written as:

$$
\alpha(v)=n(p, T) \cdot g\left(p, T, v-v_{0}\right) \cdot S(T)
$$

Where $n$ is the number density of the absorbing species, $g$ is the normalized line shape function, $v_{0}$ is the center frequency of the absorption feature, $S$ is the corresponding line strength, and $p$ and $T$ are the total pressure and the temperature of the sample, respectively. Evaluation of Eq. (3) requires quantitative knowledge of the exact line shape function. Since the line shape function is normalized to unity, integration of the absorption feature removes the dependence on the pressure of the line shape function $g$ (Eq. 3). The line strengths for the rotational-vibrational transitions used by our spectrometer are taken from the HITRAN (High Resolution TRANsmission) database (Rothman et al., 2005). It should be noted that the line strengths reported by HITRAN for the isotopic species take their natural abundance already 
1 The number density of the absorbing molecules is then related to the total pressure of the

2 sample inside the spectrometer, assuming an ideal gas, in the following way:

3

4

5

6

7 determined by a measurement of the absorption coefficient at known pressure and 8 temperature.

9

10 The isotope ratio ("delta-value") instead is given by the super-ratio of the absorption 11 coefficients of the rare and abundant isotopologues in the sample and a reference material. For

$$
n=v \frac{p}{k T}
$$
example, in the case of oxygen-18 (Kerstel, 2004): ${ }^{1}$

$$
\delta^{18} O=\frac{\left(\alpha_{18}{ }^{\text {sample }} / \alpha^{{ }_{18} O}{ }^{\text {reference }}\right)}{\left(\alpha^{{ }^{16} O}{ }^{\text {sample }} / \alpha^{16}{ }^{\text {reference }}\right)}-1
$$

In practice, the absorption coefficients of the rare and abundant isotopic species are determined almost simultaneously in the same gas, and thus also at the same temperature. However, there may be a small temperature difference between the sample and the reference spectral recordings. It is then easy to show that the isotope ratio of Eq. (5) is independent of the absolute temperature, but sensitive to the temperature differential between the sample and reference recordings (Kerstel, 2004). For this reason, the spectrometer is actively temperature

\footnotetext{
${ }^{1}$ The laser spectroscopic method determines molecular isotope ratios. It can be shown that these are practically equal to the more usual atomic isotope ratios, also for the case of $\delta^{2} \mathrm{H}$ (see Appendix I in Kerstel, 2004).
} 
1 stabilized to about $32{ }^{\circ} \mathrm{C}$ to within about $0.2{ }^{\circ} \mathrm{C}$. Considering the temperature coefficients of

2 the absorption lines in question (Kerstel et al., 2002), this reduces any temperature related

3 isotope ratio error to less than $0.2 \%$ for $\delta^{18} \mathrm{O}$ and $1.6 \%$ for $\delta^{2} \mathrm{H}$.

4 The pressure controller at the entrance of the spectrometer actively stabilizes the pressure

5 inside the spectrometer gas cell to a set value in the range of 0 to 200 mbar. A needle valve at

6 the exit of the gas cell controls the flow rate. Data presented here have been obtained at three

7 different pressure settings of 40, 100, and 160 mbar and three different flow rates of 150, 300,

8 and $600 \mathrm{~mL} / \mathrm{min}$ at standard temperature and pressure (STP).

\section{Experimental results}

\section{$11 \quad 3.1$ Microdrop generator linearity of response}

12 The linearity of the instrument was evaluated by exposing the optical spectrometer to several 13 water mixing ratio levels, starting from low humidity conditions and then stepping the 14 concentration up through a series of fixed levels, by increasing the droplet repetition 15 frequency, as shown in Figure 3a. The measurements were carried out with a flow of 150 STP $\mathrm{mL} / \mathrm{min}$. The time resolution in the figure is $1 \mathrm{~s}$ (i.e., circa 10 spectral scans were averaged to

17 produce one data point in the figure). Each concentration level was maintained for at least half 18 an hour before stepping to the next.

19 Figure $3 \mathrm{~b}$ shows, instead, two transitions where the water vapor mixing ratio decreases from 201,400 to $\sim 335 \mathrm{ppm}$, and subsequently further down to $60 \mathrm{ppm}$. From these measurements the 21 (single) exponential time constants were determined to be $5.4( \pm 0.3) \mathrm{sec}$ and $5.7( \pm 0.2) \mathrm{sec}$, respectively. These time constants are not very different from those determined previously for

23 the spectrometer only ( $\sim 3$ s) (Kerstel et al., 2006), and correspond approximately to the time 24 needed to exchange the gas in the spectrometer cavity, the injector assembly, and the tubing 
1 between them (total volume $\sim 20 \mathrm{~mL}$ ), at the current low flow through the cell $(150 \mathrm{~mL} / \mathrm{min}$ 2 STP).

3 The last 15 minutes of data belonging to Figure $3 \mathrm{a}$ at each water vapor concentration level

4 were used to determine an averaged mixing ratio value. These averaged instrument readings

5 are shown in Figure 4 versus the output of the microdrop water vapor system as calculated

6 from the drop size and repetition frequency, and the flow conditions in the injector. The

7 microdrop generator performed very well, showing a high stability and reproducibility.

8 However, above a concentration of about 3,500 ppm, the evaporation of the water droplets is

9 not complete and steady-state wetting of the bottom of the injection chamber is observed. This

10 is most evident from the increasing time needed to reach the next stable water concentration

11 level (Figure 3a). But it is also observable in Figure 4, where the data point at a calculated

12 injector mixing ratio of $7,600 \mathrm{ppm}$, shows that the measured mixing ratio is more than $20 \%$

13 too low. The solid line represents a linear fit to the lower volume mixing ratio data, excluding

14 the data with $v>4,000 \mathrm{ppm}$. The slope is $1.038( \pm 0.007)$, indicating that the spectrometer

15 overestimates the water concentration. The slope, however, falls practically within the limits

16 posed by the combined uncertainty on the droplet size $( \pm 0.4 \%)$, the flow measurement $( \pm 3 \%)$,

17 the pressure controller reading as specified by the manufacturer ( $\pm 0.5 \%$ of full scale), and the

18 frequency determination (up to $0.5 \%$ ), which together determine the volume mixing ratio of

19 the moist air stream produced by the injector.

20 Since an exact cancellation of device non-linearities between injector and spectrometer to the

21 level demonstrated in the figure is highly unlikely, we may conclude that the volume mixing

22 ratio produced by the injector is indeed linearly dependent on the repetition frequency and

23 that the response of the G2WIS device too is clearly highly linear over two orders of

24 magnitude (correlation coefficient $\geq 0.9999$ ). The linear fit in Figure 4 yields, however, a

25 small non-zero intercept of $39 \pm 6 \mathrm{ppm}$. For a given configuration and operating parameters, 
1 this offset is very stable and indicates the existence of an extra source of water with a constant

2 mixing ratio. Possible origins of this source are the background level of water vapor

3 contributed by out-gassing of the inner parts of the injector or the optical cell, or a small leak

4 present in the vacuum system, or even residual water present in the "dry- $\mathrm{N}_{2}$ " cylinder. We

5 have noted that the offset depends to some extent on the time the system is purged with dry

6 nitrogen before the first amount of water is injected. The offset is, however, particularly

7 sensitive to the flow rate. Figure 5 a shows that at a flow rate of $600 \mathrm{~mL} / \mathrm{min} \mathrm{STP}$ the offset

8 has essentially disappeared (the intercept is now $-1.8 \pm 1.7 \mathrm{ppm}$ ). This is a strong indication

9 that the origin of this water source is not the compressed nitrogen (which appears to contain

10 no measurable amount of water), but that outgassing is to blame. In addition to release of

11 water molecules adsorbed on the inner walls, trapping of moist air in dead space in the

12 injector, optical cavity, or gas connections, is a possibility. In fact, no attempt was made to

13 design an injector geometry that avoids stagnation points in the flow pattern. Also, whereas

14 the spectrometer is made from internally polished stainless steel, the injector is machined

15 from a solid aluminum block, with no special surface treatment. Most importantly, no

16 provision was made to heat (part of) the injector assembly.

17 In Figure 5a, the measured volume mixing ratios are shown as a function of the injector

18 repetition frequency at three different flow rates $(150,300$ and $600 \mathrm{~mL} / \mathrm{min})$. The

19 combination of repetition frequencies and flow rates in this case covers a volume mixing

20 range from 12 to $3,500 \mathrm{ppm}$. Flow rate and mixing ratio should be inversely proportional.

21 This is indeed approximately true: with a doubling of the flow rate the slope of the straight

22 line fit to the data decreases first by a factor of 2.09 (from $150 \mathrm{~mL} / \mathrm{min}$ to $300 \mathrm{~mL} / \mathrm{min}$ ), then

23 by a factor of 2.03 (from $300 \mathrm{~mL} / \mathrm{min}$ to $600 \mathrm{~mL} / \mathrm{min}$ ). The first is slightly outside the error

24 margin of $3 \%$ of the flow meter reading. However, it cannot be excluded that the injector

25 operating conditions have changed to produce a somewhat smaller drop size in this case. 
2 In a final test of the instrument linearity, Figure 5b shows measurements at varying droplet

3 repetition frequency and a fixed flow rate of $150 \mathrm{~mL} / \mathrm{min}$, but with the pressure controller of

4 the infrared spectrometer set to three different gas cell pressures between 40 and 160 mbar.

5 As expected, the measurements show no systematic dependence on the cavity pressure,

6 demonstrating that the data (spectral) analysis correctly accounts for pressure broadening of

7 the spectral absorption features. This also is an indication that spectrometer saturation is not

8 the cause of lower measured mixing ratios at high water concentrations.

\subsection{Isotope ratio measurements}

11 In order to calibrate the instrument, a series of measurements were performed, in which the

12 local water standards GS-22, GS-48, and GS-50, were alternatingly introduced in the 13 spectrometer.

14 Since only two micro dispenser injectors were available, one of them was used to inject two 15 different local water standards. In order to avoid possible memory effects, a clean dispenser reservoir was used for each water standard, whereas the injector capillary and PFTE tube were

17 cleaned before re-using the injector with the new water source.

18 The water mixing ratio was about $2,000 \mathrm{ppm}$, while the flow rate was set to $150 \mathrm{~mL} / \mathrm{min}$. The 19 data points in the figure are the average of the results of about 200 spectra, yielding a time 20 resolution of $20 \mathrm{~s}$. The average of the means of the two GS-48 measurement series and the 21 mean of the one GS-50 series were used to scale the raw measurements in the same manner as the VSMOW-SLAP scale correction recommended by the IAEA (Gonfiantini 1984, Hut

23 1987). Figure 6 shows the time series of the $\delta^{2} \mathrm{H}$ and $\delta^{18} \mathrm{O}$ measurements. The $\delta^{17} \mathrm{O}$

24 measurements are not considered here as they are not expected to yield information beyond 25 that provided by $\delta^{18} \mathrm{O}$, due to the very tight relation between $\delta^{17} \mathrm{O}$ and $\delta^{18} \mathrm{O}$ observed in all 
1 tropospheric water (see, e.g., Meijer and Li, 1998). The figure also shows the mean value and

2 the standard deviation for each measurement series. The GS-22 $\delta^{2} \mathrm{H}$ measurements deviate by

$34.5 \%$ and $-3.5 \%$ from the accepted value, whereas the $\delta^{18} \mathrm{O}$ measurements are about $1.4 \%$

4 too high. These numbers should be compared to the combination of the measurement error on

5 GS-22 and the accuracy with which the VSMOW-SLAP calibration curve is known at the

6 position of GS-22. In the following error analysis we use the standard deviation of the five

7 local reference water measurements, as opposed to the standard error on the mean, since the

8 measurements were calibrated on a time scale of 1 to 3 hours, long compared to the stability

9 time of the spectrometer (and caused by the necessity to thoroughly clean the injector between

10 its usage for GS-22 and GS-50). The latter was determined to be of the order of $20 \mathrm{s.}$, based

11 on an Allan variance analysis (Werle et al., 1993). This treatment is, however, beyond the

12 scope of this paper and will be published elsewhere. Spectrometer drift on the time scale of

13 hours means that the use of the standard error is likely to seriously underestimate the true

14 uncertainty in the measurements. The major contribution to drift of the spectrometer on these

15 time scales is expected to come from the temperature dependence of the line strengths. As

16 stated previously in section 2.2 , the expected temperature-induced uncertainty on the isotope

17 ratio measurements is about $1.6 \%$ and $0.2 \%$ for $\delta^{2} \mathrm{H}$ and $\delta^{18} \mathrm{O}$, respectively. These

18 uncertainties are smaller than the standard deviation of the respective spectrometer

19 measurements, such that the use of the standard deviation in the error budget is likely a

20 conservative choice. The standard deviations of the GS-48 and GS-50 isotope ratio

21 measurements translate into an uncertainty of $2.5 \%$ for $\delta^{2} \mathrm{H}$ and $0.25 \%$ or $\delta^{18} \mathrm{O}$ on the

22 accuracy with which we can know the isotope ratio values of GS-22. We have not considered

23 the uncertainties in the IRMS determinations of the isotope ratios, given that these are about

24 one order of magnitude smaller than the standard deviations of the laser spectrometer results. 
1 Combining the standard deviations of the GS-22 determinations with the calibration

2 uncertainty, we conclude that the $\delta^{2} \mathrm{H}$ determinations are within 1 to 1.5 times the 1 -sigma

3 measurement uncertainty of the accepted value. The $\delta^{18} \mathrm{O}$ determinations are approximately

43.5 times the 1-sigma uncertainty removed from the accepted value for GS-22. This deviation

5 is larger than expected and may indicate that we have slightly underestimated the

6 (temperature) stability of the spectrometer in our error budget. Fractionation, due to, e.g.,

7 condensation in the system, can be excluded as it should have affected the deuterium

8 measurement too.

10 Finally, the injector is used to investigate the dependence of the precision of the isotope ratio

11 measurements on the water volume mixing ratio. The level of precision is directly determined

12 by the signal-to-noise ratio of the spectral features of the rare and abundant isotopologues, and

13 thus can be expected to deteriorate at exceedingly small signal levels. The results are reported

14 in Figure 7, which shows the 1-sigma standard deviation determined for 2-second averaged

15 isotope ratio determinations for water mixing ratios from 32 to $7,600 \mathrm{ppm}$. It is clear that,

16 starting at a water vapor mixing ratio of $\sim 2,000 \mathrm{ppm}$ the standard deviation of the oxygen

17 isotope ratios remains essentially constant with increasing mixing ratio. Only the deuterium

18 precision continues to improve, which is easily understood if one realizes that the deuterium

19 line in the spectrum is almost one order of magnitude weaker than the $\mathrm{H}^{18} \mathrm{OH}$ line.

20 By co-adding spectra, the precision continues to improve up to a total averaging time of about

$2120 \mathrm{~s}$. The best precisions obtained are then $1.3 \%$, $0.4 \%$, and $0.15 \%$ or for $\delta^{2} \mathrm{H}, \delta^{17} \mathrm{O}$, and $\delta^{18} \mathrm{O}$

22 respectively.

$24 \quad 4$ Conclusion 
1 In this paper, we demonstrate that a microdrop generator system provides a simple and

2 efficient method for calibrating an optical isotope ratio spectrometer for the on-line

3 measurement of isotope abundance ratios of atmospheric moisture. The accuracy of the

4 volume mixing ratio was dominated by the limited accuracy (3\%) of the mass flow meter. The

5 stability of the mixing ratio is almost one order of magnitude better. For a good

6 reproducibility of the mixing ratio care should be taken to stabilize the differential pressure

7 over the nozzle. The device was demonstrated at mixing ratios from 12 to over 5,000 ppm.

8 Lower mixing ratios can be produced, but the flow rate should then be sufficiently high ( $\sim 1$

$9 \mathrm{~L} / \mathrm{min}$ or higher). At lower flow rates, the droplet frequency would need to be very low $(<1$

$10 \mathrm{~Hz}$ ), leading to a periodically oscillating mixing ratio and flow stagnation points in the

11 injection chamber may contribute to a background moisture level. Higher mixing ratios can be

12 obtained if condensation (and thus isotope fractionation) in the injector can be avoided, for

13 example by increasing the path the droplets can travel before hitting the wall of the injection

14 chamber, and by heating the latter. For a rapid change-over between different isotope

15 standards it is, however, necessary to use one injector for each standard material used.

17 The microdrop generator was used to investigate the linearity of response and the accuracy 18 and precision of a sensitive infrared laser based spectrometer for on-line water vapor isotope 19 measurements. The $\delta^{17} \mathrm{O}$ and $\delta^{18} \mathrm{O}$ precisions reach their minimum values at around 1,000 $20 \mathrm{ppm}$ and remain essentially constant at higher mixing ratios. The level of precision improved 21 with averaging over 20 seconds, reaching values of $1.3 \%$, $0.4 \%$, and $0.15 \%$, for $\delta^{2} \mathrm{H}, \delta^{17} \mathrm{O}$, 22 and $\delta^{18} \mathrm{O}$, respectively. 
1 The microdrop generator is able to reach much lower water vapor mixing ratios than the

2 direct, non diluted output of a dew-point generator or bubbler device, and is characterized by

3 the absence of isotope fractionation between the supplied liquid phase water and the produced

4 moist air stream. It is also compact and requires a minimum amount of water, making it ideal

5 to calibrate an atmospheric moisture isotope spectrometer, also in field situations.

6

\section{Acknowledgement}

8 The present work was funded by the Dutch Foundation for Fundamental Research on Matter

9 (FOM, program number 99MAP10). We are grateful to Henk Been for his excellent technical

10 support, and to the anonymous reviewers for their careful reading of, and useful comments on

11 the manuscript.

12

13

14

15

16

17

18

19

20

21

22

23

24 


\section{References}

2

3 Baker, L., I. Franchi, J. Maynard, I. Writght, and C. Pillinger, 2002: A technique for the 4 determination of ${ }^{18} \mathrm{O} /{ }^{16} \mathrm{O}$ and ${ }^{17} \mathrm{O} /{ }^{16} \mathrm{O}$ isotopic ratios in water from small liquid and solid 5 samples. Analytical Chemistry, 74, 1665-1673.

6

7 Berden, G., R. Peeters, G. and Meijer, 2000: Cavity ring-down spectroscopy: experimental 8 schemes and applications. Int. Rev. Phys. Chem., 19(4), 565-607.

9

10 de Gans, B.-J., and U.S. Schubert, 2004: Inkjet printing of well-defined polymer dots and 11 arrays. Langmuir, 20, 7789-7793.

12

13 Forster, P. M., K. P. and Shine, 2002: Assessing the climate impact of trends in stratospheric water vapor, Geophysical Research Letters, 29, pp.1086.

16 Franz, P. and Th. Röckmann, 2004: A new continuous flow isotope ratio mass spectrometry 17 system for the analysis of $\delta^{2} \mathrm{H}, \delta^{17} \mathrm{O}$ and $\delta^{18} \mathrm{O}$ of small $(120 \mu \mathrm{g})$ water samples in atmospheric application. Rapid Commun. Mass Spectrom., 18, 1429-1435.

20 Franz, P. and Th. Röckmann, 2005: High-precision isotope measurements of $\mathrm{H}_{2}{ }^{16} \mathrm{O}, \mathrm{H}_{2}{ }^{17} \mathrm{O}$, $21 \mathrm{H}_{2}{ }^{18} \mathrm{O}$, and the $\Delta^{17} \mathrm{O}$-anomaly of water vapor in the southern lowermost stratosphere. Atmos. 22 Chem. Phys., 5, 2949-2959. 
1 Gonfiantini, R., 1984: Advisory Group Meeting on Stable Isotope Reference Samples for

2 Geochemical and Hydrological Investigations; IAEA: Vienna.

3

4 Hanisco, T. F., and Coauthors, 2007: Observations of deep convective influence on

5 stratospheric water vapor and its isotopic composition. Geophys. Res. Lett., 34, L04814, 6 doi:10.1029/2006GL027899.

7

8 Helliker, B. R., J.S. Roden, C.S. Cook, and J.R. Ehleringer, 2002: A rapid and precise method

9 for sampling and determining the oxygen isotope ratio of atmospheric water vapor. Rapid

10 Commun. Mass Spectrom., 16, 929-932.

12 Helsen, M. M., R. S. W. van de Wal, M. R. van den Broeke, E. R. Th. Kerstel, V. Masson-

13 Delmotte, H. A. J. Meijer, C. H. Reijmer, M. P. Scheele, 2004: Modelling the isotopic 14 composition of snow using backward trajectories: a particular precipitation event in Dronning 15 Maud Land, Antarctica. Annals Glaciol., 39 (1), 293-299.

17 Hoffmann, G., J. Jouzel, and V. Masson, 2000: Stable water isotopes in atmospheric general 18 circulation models. Hydrol. Processes, 14, 1385-1406.

Hut, G., 1987: Report to the Director General, International Atomic Energy Agency, Vienna.

Iannone, R.Q., S. Kassi, M. Chenevier, H.-J. Jost, D. Romanini, H. A. J. Meijer, and E. R. Th. Kerstel, 2009: In situ water vapor isotope measurements onboard of the M55-Geophysica 24 during the 2006 AMMA campaign. In preparation. 
1 Keith, W., 2000: Stratospheric-tropospheric exchange: Inferences from the isotopic 2 composition of water vapor. J. Geophys. Res., 105, 15167-15174.

3

4 Kirk-Davidoff, D.B., J.G. Anderson, E.J. Hintsa, and D.W. Keith, 1999: The effect of climate

5 change on ozone depletion through changes in stratospheric water vapor. Nature, 402, 3996401.

8 Kerstel, E.R.T., R. van Trigt, N. Dam, J. Reuss, H.A.J. Meijer, 1999: Simultaneous 9 determination of the ${ }^{2} \mathrm{H} /{ }^{1} \mathrm{H},{ }^{17} \mathrm{O} /{ }^{16} \mathrm{O}$, and ${ }^{18} \mathrm{O} /{ }^{16} \mathrm{O}$ isotope abundance ratios in water by means of laser spectrometry. Anal. Chem. 71, 5297-5303.

Kerstel, E. R. Th., G. Gagliardi, L. Gianfrani, H.A.J. Meijer, R. van Trigt, R. Ramaker, 2002:

13 Determination of the ${ }^{2} \mathrm{H} /{ }^{1} \mathrm{H},{ }^{17} \mathrm{O} /{ }^{16} \mathrm{O}$, and ${ }^{18} \mathrm{O} /{ }^{16} \mathrm{O}$ isotope ratios in water by means of tunable 14 diode laser spectroscopy at $1.39 \mu \mathrm{m}$. Spectrochimica Acta Part A, 58, 2389-2396.

Kerstel, E. R. Th., 2004: Isotope Ratio Infrared Spectrometry, in Handbook of Stable Isotope Analytical Techniques, ed. P.A. de Groot, Elsevier, chapter 34, pp. 759-787, Elsevier, Amsterdam.

Kerstel, E. R. Th., H. A. J. Meijer, 2005: Optical isotope ratio measurements in hydrology. In

21 Isotopes in the water cycle: Past, present and future of a developing science., Aggarwal, $\mathrm{P}$. K.; Gat, J. R.; Froehlich, K., Eds. Kluwer: Dordrecht, the Netherlands; Vol. IAEA Hydrology Section, Chapter 9, pp. 109-124. 
1 Kerstel, E. R. Th., R.Q. Iannone, M. Chenevier, S. Kassi, H.-J. Jost, and D. Romanini, 2006:

2 A Water Isotope $\left({ }^{2} \mathrm{H},{ }^{17} \mathrm{O}\right.$, and $\left.{ }^{18} \mathrm{O}\right)$ Spectrometer based on Optical-Feedback Cavity

3 Enhanced Absorption For In-situ Airborne Applications. Appl. Phys. B, 85(2-3), 397-406.

4

5 Kerstel, E.R.Th. and L. Gianfrani, 2008: Advances in laser-based isotope ratio measurements:

6 selected applications. Appl. Phys. B, doi: 10.1007/s00340-008.

7

8 Lee, E.R., (Boca Raton), 2002: Microdrop Generation, CRC Press.

Lee, X., S. Sargent, R. Smith, B. Tanner, 2005: In Situ Measurement of the Water Vapor

${ }^{18} \mathrm{O} /{ }^{16} \mathrm{O}$ Isotope Ratio for Atmospheric and Ecological Applications. J. Atmos. Ocean.

12 Technol., 22, 555-565.

Lis, G., L.I. Wassenaar, M.J. Hendry, 2008: High-Precision Laser Spectroscopy D/H and ${ }^{18} \mathrm{O} /{ }^{16} \mathrm{O}$ Measurements of Microliter Natural Water Samples. Anal. Chem., 80, 287-293. http://www.lgrinc.com (last date of access July 1, 2008). and cavity enhanced spectroscopy using diode lasers. Ann. Rep. Prog. Chem., Sect C, 101, $100-142$.

24 Meijer, H., and W. Li, 1998: The use of electrolysis for accurate ${ }^{17} \mathrm{O}$ and ${ }^{18} \mathrm{O}$ isotope 25 measurements in water isotopes. Isotopes Environ. Health Stud., 34, 349-369. 
2 Meinhart, C. D., and H. Zhang, 2000: The flow structure inside a microfabricated inkjet 3 printhead. Journal of Microelectromechanical System, 9, 67-75.

4

5 Morville, J., D. Romanini, A. Kachanov, M. Chenevier, 2004: Two schemes for trace 6 detection using cavity ring-down spectroscopy. Appl. Phys. B, 78, 465-476.

7

8 Morville, J., S. Kassi, M. Chenevier, and D. Romanini, 2005: Fast, low-noise, mode-by9 mode, cavity-enhanced absorption spectroscopy by diode-laser self-locking. Appl. Phys. B, 80, 1027-1038.

Moyer, E. J., F. W. Irion, Y. L. Yung, M. R. Gunson, 1996: ATMOS stratospheric deuterated water and implications for troposphere-stratosphere transport. Geophys. Res. Lett., 23 (17), 2385-2388.

Picarro Inc., 480 Oakmead Parkway, Sunnyvale, CA 94085, USA, http://www.picarro.com (last date of access July 1, 2008).

Pielke, Sr. R. A., 2001: Influence of the spatial distribution of vegetation and soils on the prediction of cumulus convective rainfall. Rev. Geophys., 39, 151-177.

Rautian, S.G., and I.C. Sobel'man, 1967: The effect of collisions on the Doppler broadening of spectral lines. Sov. Phys. Usp., 9, 701-716. 
1 Rothman, L.S., and Coauthors, 2005: HITRAN molecular database. J. Quant. Spectrosc.

2 Radiat. Transf., 96, 139-204.

3

4 Schmidt, G.A., G. Hoffmann, D.T. Shindell, Y. Hu, 2005: Modelling atmospheric stable 5 water isotopes and the potential for constraining cloud processes and stratosphere6 troposphere water exchange. J. Geophys. Res., 110 D, 21314.

8 Squires, T.M., and S.R. Quake, 2005: Microfluidics: fluid physics on the nanoliter scale. Rev. 9 Of Modern Physics, 77, 977- 1026.

11 St. Clair, J. M., Hanisco T. F., Weinstock E. M., Moyer E. J., Sayres D. S., Smith J. B., 12 Lockwood R., and Anderson J. G., 2008: A new photolysis laser-induced fluorescence 13 instrument for the detection of $\mathrm{H}_{2} \mathrm{O}$ and $\mathrm{HDO}$ in the lower stratosphere, Rev. Sci. Instrum., 79, $14 \quad 064101$

Toon, B., E. Jensen, J. Holton, J. Logan, P. Newman, R. J. Salawitch, D. Starr, D. Waugh,

17 P.O. Wennberg, 2003: Draft of Tropical Composition, Cloud and Climate Coupling 18 Experiment (TC4). (NASA Goddard Space Flight Center, MD). 19 http://www.espo.nasa.gov/tc4/science.php.

21 Wang, X.F., and D. Yakir, 2000: Using stable isotopes of water in evapotranspiration studies. 22 Hydrol. Proc., 14 (8), 1407-1421. 
1 Werle, P., R. Mucke, F. Slemr, 1993: Limits of signal averaging in atmospheric trace gas

2 monitoring by tuneable diode-laser absorption spectroscopy. Applied Physics B-Photophysics

3 and Laser Chemistry, 57 (2), 131-139.

4

5 Werle, P., C. Dyroff, A. Zahn, P. Mazzinghi, and F. D’Amato, 2005: A new concept for

6 sensitive in situ stable isotope ratio infrared spectroscopy based on sample modulation.

7 Isotopes in Environmental and Health Studies, 41, 323-333

8

9 Werner, M., and M. Heimann, 2002: Modeling interannual variability of water isotopes in

10 Greenland and Antarctica. J. Geophys. Res., 107(D1). (10.1029/2001JD900253.)

12 West, A.G., S. J. Patrickson, and J. R. Ehleringer, 2006: Water extraction times for plant and 13 soil materials used in stable isotope analysis. Rapid Commun. Mass Spectrom., 20, 1317141321.

16 William, D.G., and Coauthors, 2004: Components of evapotranspiration in an olive orchard 17 determined by eddy covariance, sap flow and stable isotope techniques. Agric. For. Met., 125, $18 \quad 241-258$.

20 Yakir, D., and L. da S.L. Sternberg, 2000: The use of stable isotopes to study ecosystem gas 21 exchange. Oecologia, 123, 297-311.

23 Yepez, E.A., D.G. Williams, R.L Scott., G. Lin, 2003: Partitioning overstory and understory 24 evapotranspiration in a semi-arid woodland ecosystem from the isotopic composition of water 25 vapor. Agric. For. Met., 119, 53-68. 


\section{Figure Captions}

2

3 Figure 1: Four photographs of the CCD camera screen taken at different stroboscope delay

4 times. Part of the glass capillary of the droplet generator can be seen, in addition to the droplet

5 formation. The third frame shows the ejection of the droplet, which is followed by the

6 retraction of the water column back into the capillary.

8 Figure 2: Schematic diagram of the experimental arrangement. Water droplets, generated by 9 the micro dispenser, are injected directly into a flow of high-purity nitrogen. A pressure controller keeps the pressure in the gas line to $\sim 30$ mbar above ambient pressure in order to avoid liquid leaking from the injector. The flow rate through the optical cavity is controlled by a pressure controller before the cavity, in combination with a needle valve after the cavity.

Figure 3: (a) Response of the laser spectrometer to step-wise changes of the water mixing ratio of a moist air flow of only $150 \mathrm{~mL} / \mathrm{min}$. The water concentration was increased by increasing the droplet frequency of the nozzle injector. The pressure inside the optical cavity

17 of the spectrometer was kept at 100 mbar. (b) Response of the spectrometer to two subsequent step-downs in the water concentration. The time constants are 5.4(3) sec and 5.7(2) sec for the transitions from 1,400 to $335 \mathrm{ppm}$, and from 335 to $60 \mathrm{ppm}$, respectively (the exponential fits are shown as a solid lines). The slow onset of the first transition is due to the manual, gradual change in injector frequency.

23 Figure 4: Response of the laser spectrometer as a function of the calculated volume mixing 24 ratio of the injector system. A highly linear relationship is observed between the laser 25 spectrometer signal strength and the nozzle injector water concentration over almost three 
1 orders of magnitude. Above about 3,500 ppm, the droplets no longer evaporate completely

2 and liquid formation is observed in the injector chamber.

3

4 Figure 5: Laser spectrometer response as a function of the injector mixing ratio with (a) the

5 pressure inside the optical cavity set to 100 mbar and flow rates of $150(\square), 300(\Delta)$, and 600

$6 \mathrm{~mL} / \mathrm{min}(\diamond)$, and (b) a constant flow of $150 \mathrm{~mL} / \mathrm{min}$, but different cavity pressures of $40(\circ)$,

$7100(\diamond)$, and 160 mbar $(\square)$. The results show that, as expected, the mixing ratio is essentially

8 inversely proportional to the flow rate and that there is no systematic dependence on the 9 cavity pressure.

11 Figure 6: $\delta^{2} \mathrm{H}$ and $\delta^{18} \mathrm{O}$ measurements of three local reference waters, GS-22, GS-48, and GS1250 , with well-known isotope ratios. The GS-48 and GS-50 reference materials were used to 13 perform a VSMOW-SLAP style calibration. The isotope ratios of GS-22 are recovered to 14 within 1.5 and 3.5 times the 1-sigma uncertainty level for $\delta^{2} \mathrm{H}$ and $\delta^{18} \mathrm{O}$, respectively. The 15 water volume mixing ratio is roughly $2,000 \mathrm{ppm}$.

17 Figure 7: The standard deviation of the isotope ratio measurements versus the water volume 18 mixing ratio. The data represent 2-second averages. 


\section{Figures}

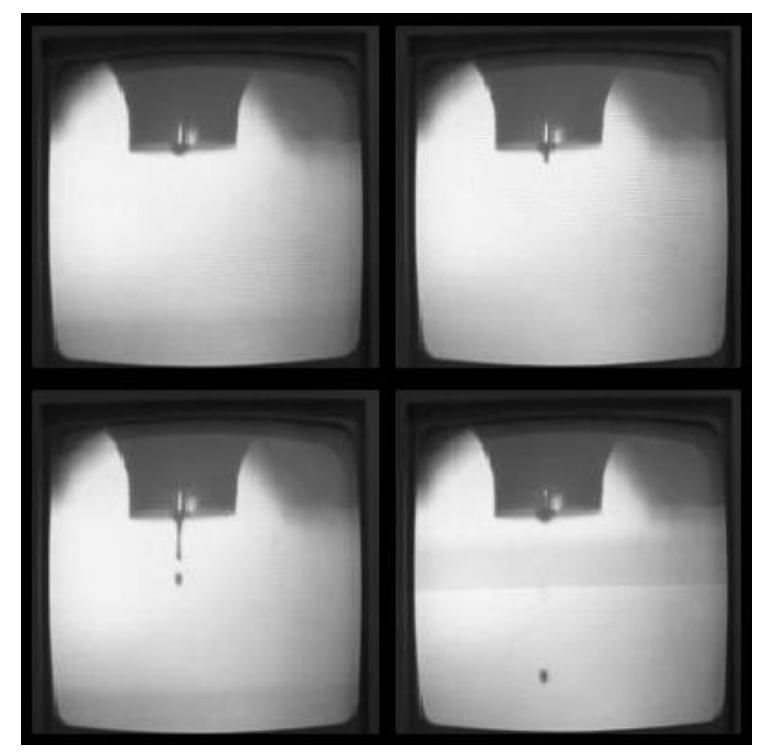

Figure 1: Four photographs of the CCD camera screen taken at different stroboscope delay times. Part of the glass capillary of the droplet generator can be seen, in addition to the droplet formation. The third frame shows the ejection of the droplet, which is followed by the retraction of the water column back into the capillary. 


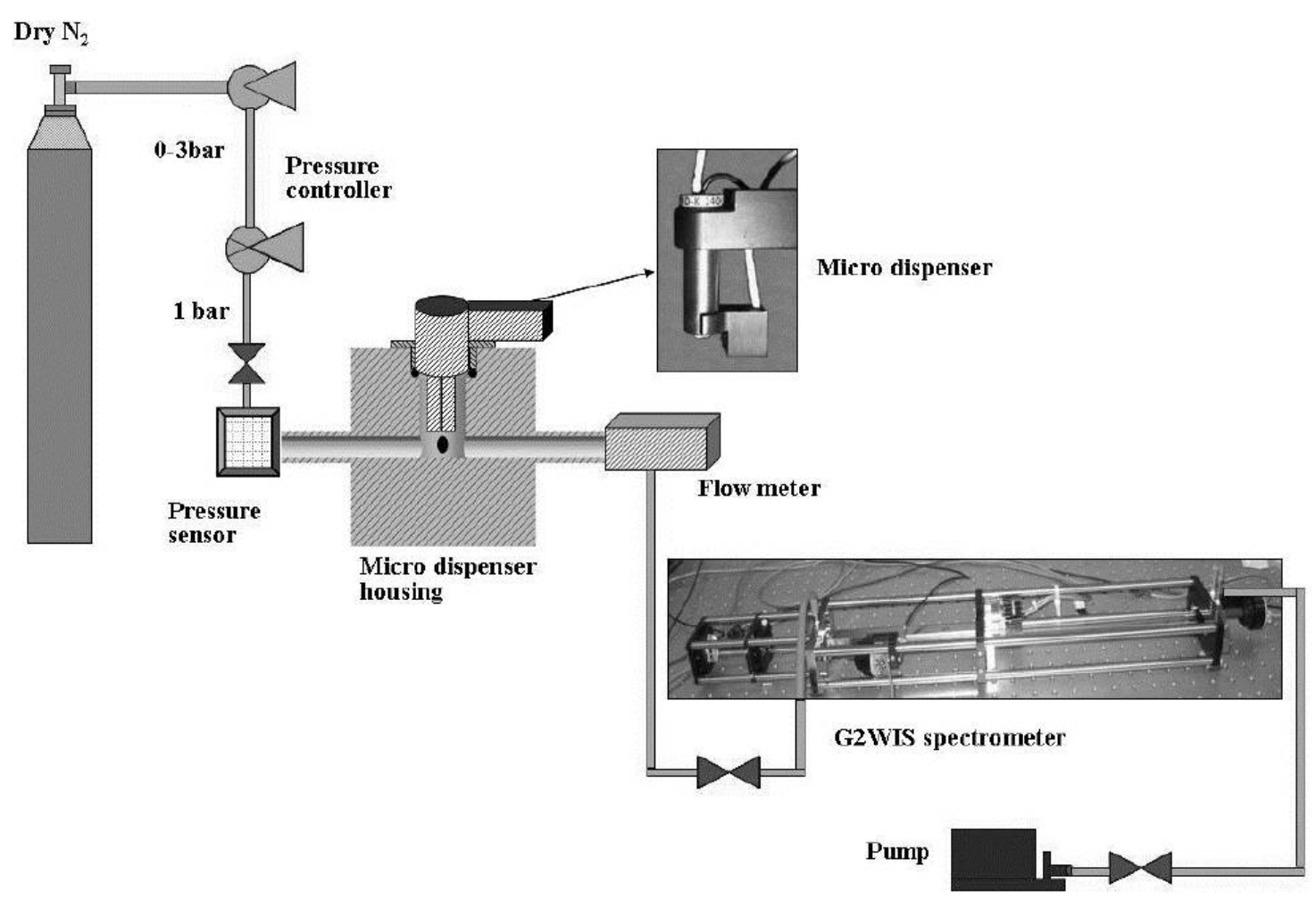

Figure 2: Schematic diagram of the experimental arrangement. Water droplets, generated by the micro dispenser, are injected directly into a flow of high-purity nitrogen. A pressure controller keeps the pressure in the gas line to $\sim 30$ mbar above ambient pressure in order to avoid liquid leaking from the injector. The flow rate through the optical cavity is controlled by a pressure controller before the cavity, in combination with a needle valve after the cavity. 

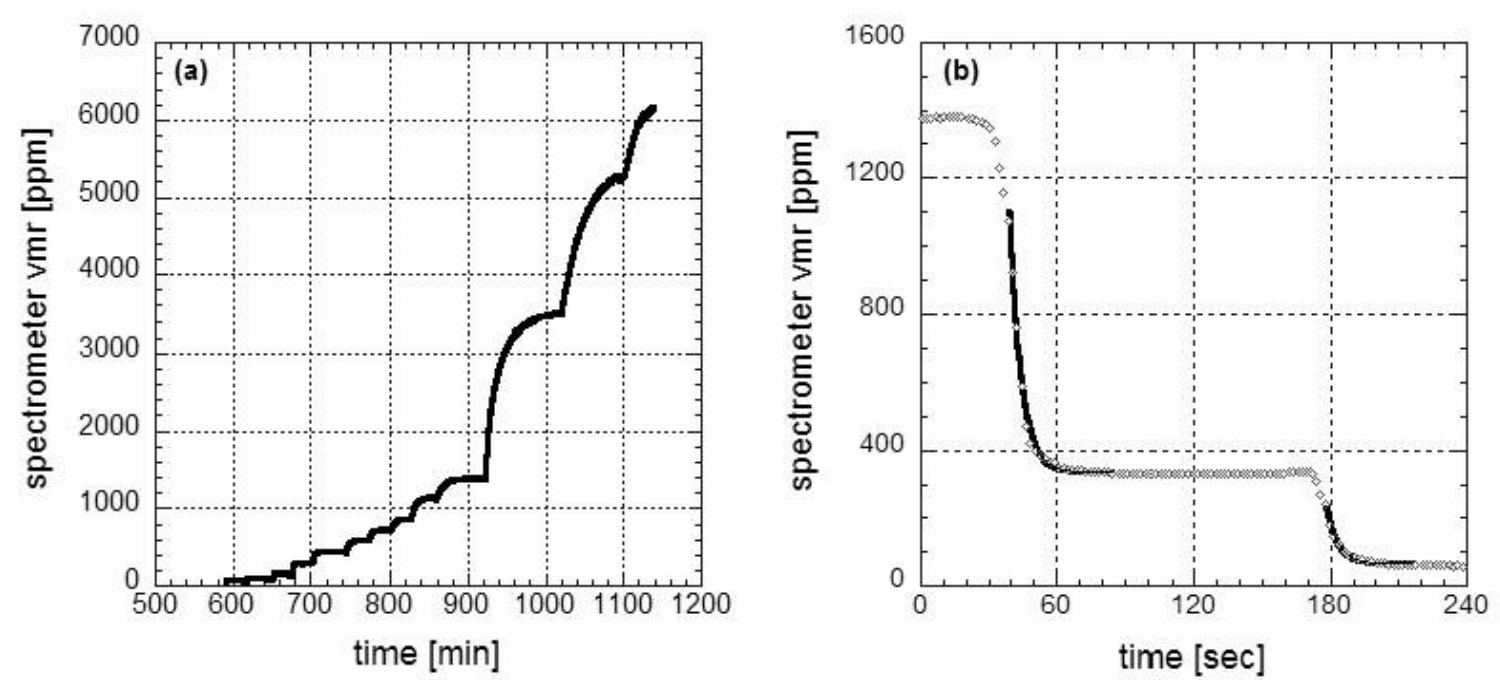

Figure 3: (a) Response of the laser spectrometer to step-wise changes of the water mixing ratio of a moist air flow of only $150 \mathrm{~mL} / \mathrm{min}$. The water concentration was increased by increasing the droplet frequency of the nozzle injector. The pressure inside the optical cavity of the spectrometer was kept at 100 mbar. (b) Response of the spectrometer to two subsequent step-downs in the water concentration. The time constants are 5.4(3) sec and 5.7(2) sec for the transitions from 1,400 to $335 \mathrm{ppm}$, and from 335 to $60 \mathrm{ppm}$, respectively (the exponential fits are shown as a solid lines). The slow onset of the first transition is due to the manual, gradual change in injector frequency. 


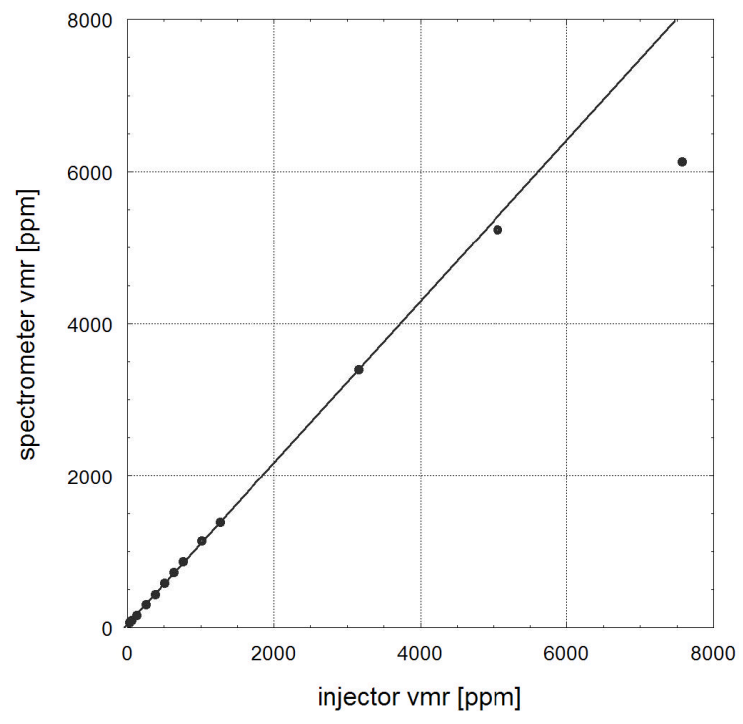

Figure 4: Response of the laser spectrometer as a function of the calculated volume mixing ratio of the injector system. A highly linear relationship is observed between the laser spectrometer signal strength and the nozzle injector water concentration over almost three orders of magnitude. Above about 3,500 ppm, the droplets no longer evaporate completely and liquid formation is observed in the injector chamber. 

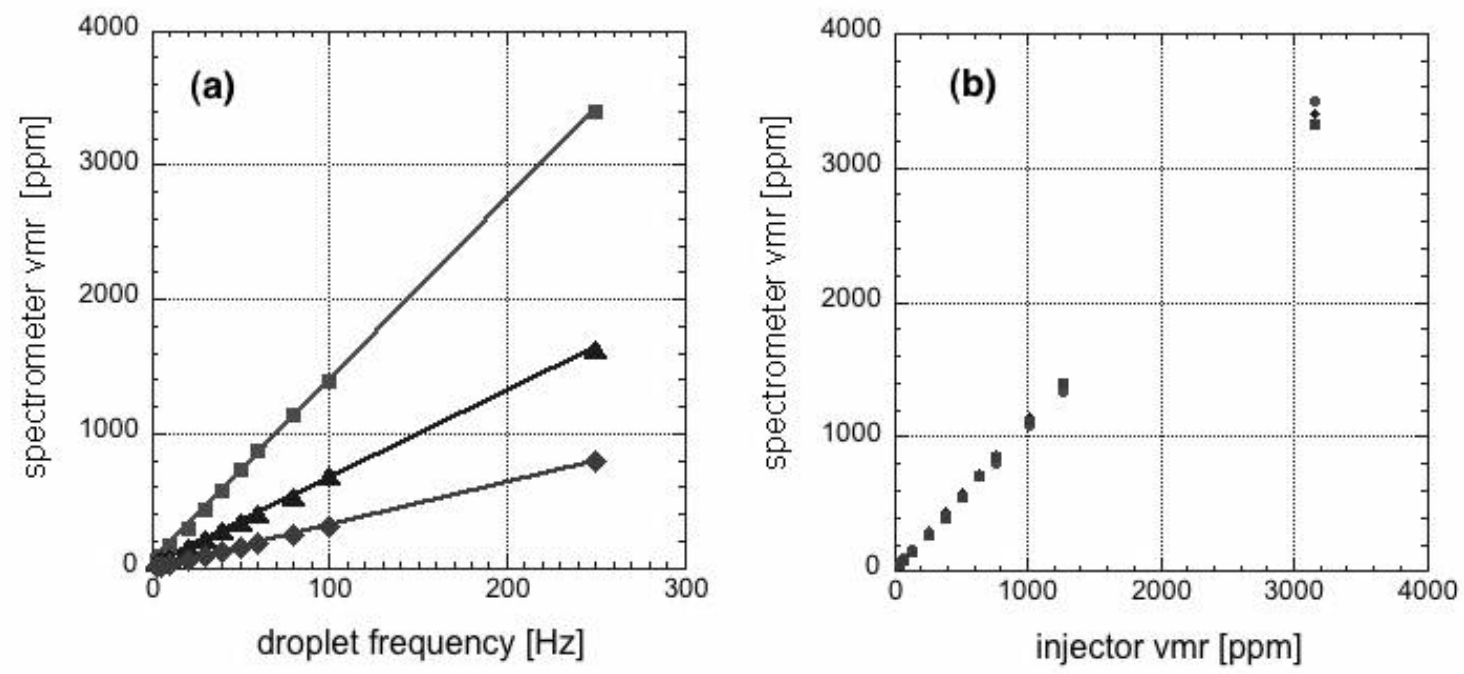

Figure 5: Laser spectrometer response as a function of the injector mixing ratio with (a) the pressure inside the optical cavity set to 100 mbar and flow rates of $150(\square), 300(\Delta)$, and 600 $\mathrm{mL} / \mathrm{min}(\diamond)$, and (b) a constant flow of $150 \mathrm{~mL} / \mathrm{min}$, but different cavity pressures of $40(\circ)$, $100(\diamond)$, and 160 mbar $(\square)$. The results show that, as expected, the mixing ratio is essentially inversely proportional to the flow rate and that there is no systematic dependence on the cavity pressure. 

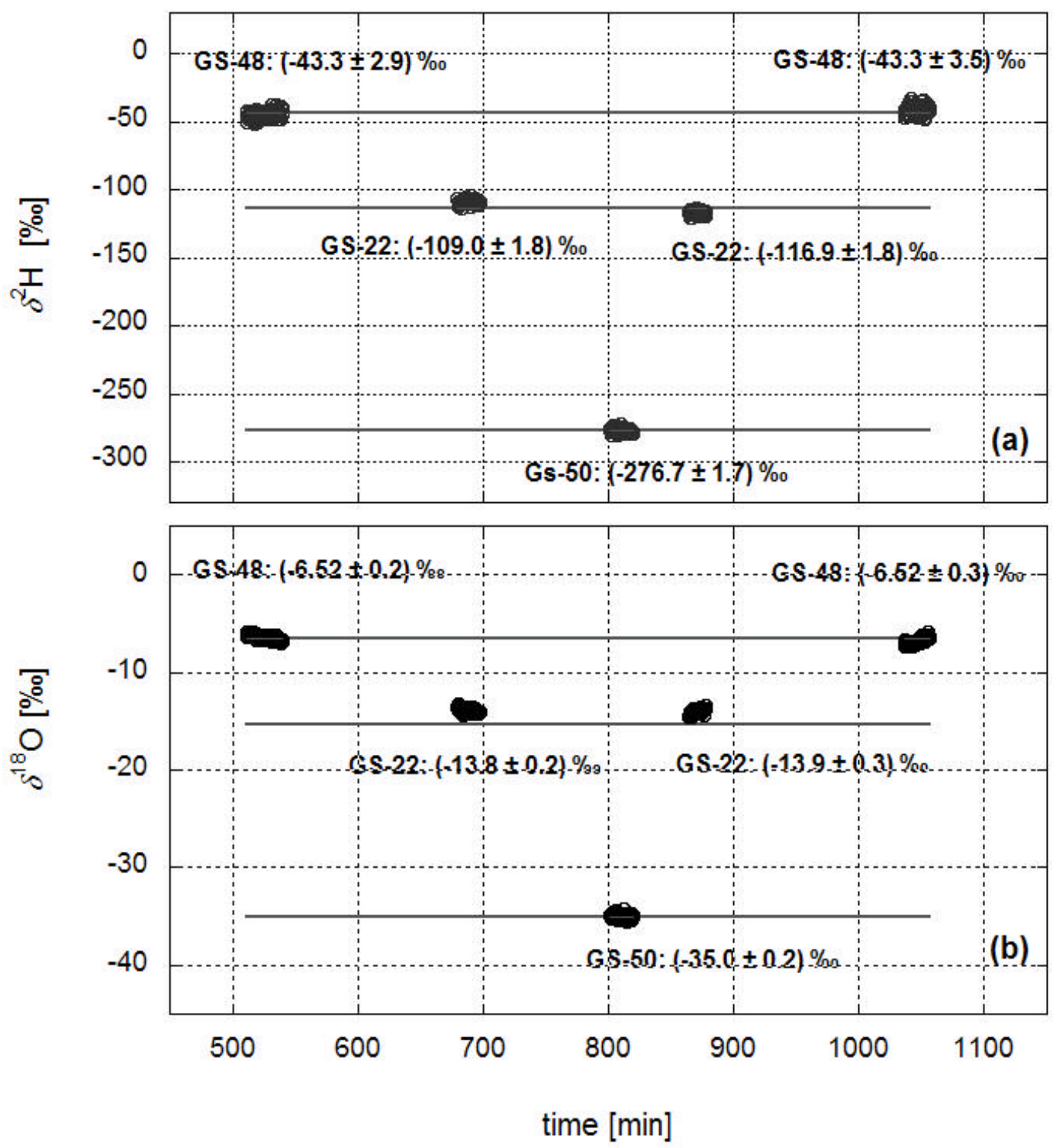

Figure 6: $\delta^{2} \mathrm{H}$ and $\delta^{18} \mathrm{O}$ measurements of three local reference waters, GS-22, GS-48, and GS50, with well-known isotope ratios. The GS-48 and GS-50 reference materials were used to perform a VSMOW-SLAP style calibration. The isotope ratios of GS-22 are recovered to within 1.5 and 3.5 times the 1 -sigma uncertainty level for $\delta^{2} \mathrm{H}$ and $\delta^{18} \mathrm{O}$, respectively. The water volume mixing ratio is roughly $2,000 \mathrm{ppm}$. 


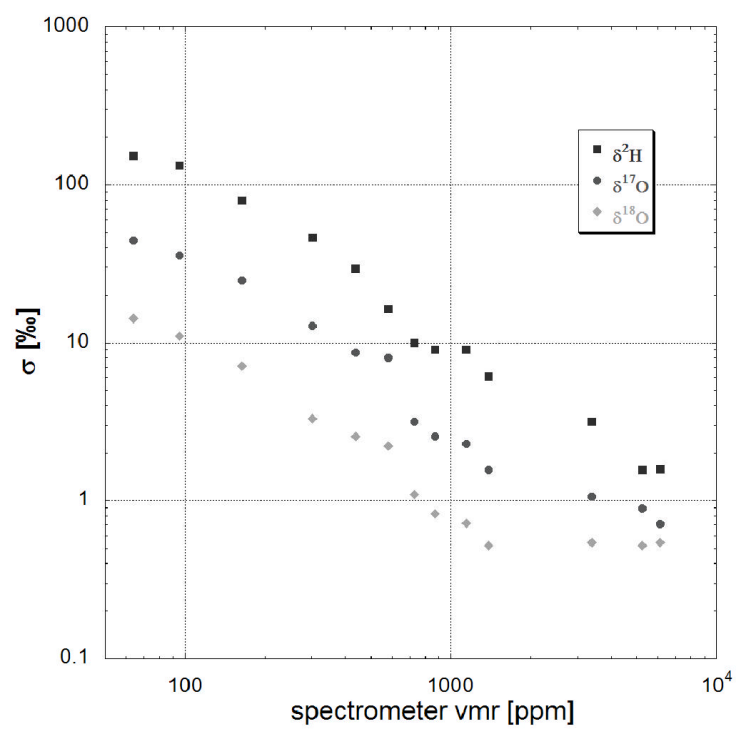

Figure 7: The standard deviation of the isotope ratio measurements versus the water volume mixing ratio. The data represent 2 -second averages. 